\title{
Histological evaluation of AMPK signalling in primary breast
}

\section{cancer}

\author{
Sirwan M Hadad*1, Lee Baker1, Philip R Quinlan ${ }^{1}$, Katherine E Robertson ${ }^{2}$, \\ Susan E Bray ${ }^{1}$, George Thomson², David Kellock¹, Lee B Jordan², \\ Colin A Purdie ${ }^{2}$, David G Hardie ${ }^{3}$, Stewart Fleming 2 and
} Alastair M Thompson ${ }^{1}$

\begin{abstract}
Address: ${ }^{1}$ Department of Surgery and Molecular Oncology, Ninewells Hospital and Medical School, Dundee, UK, ${ }^{2}$ Department of Pathology and Neuroscience, Ninewells Hospital and Medical School, Dundee, UK and ${ }^{3}$ Division of Molecular Physiology, College of Life Sciences, University of Dundee, Dundee, UK

Email: Sirwan M Hadad* - s.hadad@dundee.ac.uk; Lee Baker - l.baker@dundee.ac.uk; Philip R Quinlan - p.quinlan@dundee.ac.uk; Katherine E Robertson - k.e.robertson@dundee.ac.uk; Susan E Bray - s.e.bray@dundee.ac.uk; George Thomson - grorge.thomson@nhs.net; David Kellock - d.b.kellock@dundee.ac.uk; Lee B Jordan - lee.jordan@nhs.net; Colin A Purdie - Colin.purdie@nhs.net;

David G Hardie - d.g.hardie@dundee.ac.uk; Stewart Fleming - s.fleming@dundee.ac.uk; Alastair M Thompson - a.m.thompson@dundee.ac.uk

* Corresponding author
\end{abstract}

Published: I September 2009

BMC Cancer 2009, 9:307 doi:10.1 I86/147/-2407-9-307
Received: 10 March 2009

Accepted: I September 2009

This article is available from: http://www.biomedcentral.com/I47I-2407/9/307

(C) 2009 Hadad et al; licensee BioMed Central Ltd.

This is an Open Access article distributed under the terms of the Creative Commons Attribution License (http://creativecommons.org/licenses/by/2.0), which permits unrestricted use, distribution, and reproduction in any medium, provided the original work is properly cited.

\begin{abstract}
Background: AMP-activated protein kinase (AMPK) acts as a cellular fuel gauge that responds to energy stress by suppressing cell growth and biosynthetic processes, thus ensuring that energyconsuming processes proceed only if there are sufficient metabolic resources. Malfunction of the AMPK pathway may allow cancer cells to undergo uncontrolled proliferation irrespective of their molecular energy levels. The aim of this study was to examine the state of AMPK phosphorylation histologically in primary breast cancer in relation to clinical and pathological parameters.

Methods: Immunohistochemistry was performed using antibodies to phospho-AMPK (PAMPK), phospho-Acetyl Co-A Carboxylase (PACC) an established target for AMPK, HER2, ER $\alpha$, and Ki67 on Tissue Micro-Array (TMA) slides of two cohorts of 117 and 237 primary breast cancers. The quick score method was used for scoring and patterns of protein expression were compared with clinical and pathological data, including a minimum 5 years follow up.

Results: Reduced signal, compared with the strong expression in normal breast epithelium, using a PAMPK antibody was demonstrated in I0I/II3 (89.4\%) and $217 / 236$ (9I.9\%) of two cohorts of patients. $p A C C$ was significantly associated with $p A M P K$ expression $(p=0.007 \& p=0.014$ respectively). For both cohorts, reduced PAMPK signal was significantly associated with higher histological grade $(p=0.010 \& p=0.021$ respectively $)$ and axillary node metastasis $(p=0.061$ \& $p$ $=0.039$ respectively). No significant association was found between PAMPK and any of HER2, ER $\alpha$, or Ki67 expression, disease-free survival or overall survival.

Conclusion: This study extends in vitro evidence through immunohistochemistry to confirm that AMPK is dysfunctional in primary breast cancer. Reduced signalling via the AMPK pathway, and the inverse relationship with histological grade and axillary node metastasis, suggests that AMPK reactivation could have therapeutic potential in breast cancer.
\end{abstract}




\section{Background}

AMP-activated protein kinase (AMPK) is an intracellular energy-sensing kinase that is inactive unless it has been phosphorylated by upstream kinases at a specific threonine residue (Thr-172) within the kinase domain. Phosphorylation at Thr-172 and consequent activation occurs in response to metabolic stresses that deplete cellular energy levels and thus increase the AMP/ATP ratio [1,2]. Activation of AMPK can be assessed using a phosphospecific antibody (anti-pAMPK) that recognizes either catalytic subunit isoform ( $\alpha 1$ or $\alpha 2$ ), but only when phosphorylated at Thr-172. AMPK is proposed as a "fuel gauge" that monitors changes in the energy status of cells $[2,3]$. It is activated by metabolic stresses that inhibit ATP production such as glucose deprivation [4], ischaemia [5], or hypoxia [6], or by stresses that accelerate ATP consumption such as contraction in skeletal muscle [7]. Once activated, AMPK down-regulates energy-consuming processes, including cell proliferation, thus ensuring that these processes only proceed if there are sufficient metabolic resources available [8]. AMPK switches on catabolic pathways that generate ATP, while switching off biosynthetic pathways and other processes that consume ATP, and hence has a key role in maintaining energy balance both at the single cell and the whole body levels [2,9].

One direct downstream target of AMPK is acetyl-Coenzyme A carboxylase (ACC). In its active, de-phosphorylated form, ACC catalyzes the conversion of acetyl-CoA to malonylCoA in the de novo lipid synthesis pathway $[3,10,11]$. When it is inactivated by phosphorylation, a decrease in malonyl-CoA occurs, thereby increasing the mitochondrial import and oxidation of long chain fatty acids (LCFAs), resulting in the generation of ATP [12]. ACC exists as two isoforms, ACC1/a and ACC2/b, with ACC1 being thought to produce the pool of malonyl-CoA involved in fatty acid synthesis, while ACC2 is thought to produce the mitochondrial pool that regulates fatty acid oxidation $[13,14]$. AMPK phosphorylates ACC1 at multiple residues, although phosphorylation at a single serine (Ser-79 in rat and Ser-80 in human ACC1) accounts for the resulting inactivation $[15,16]$. AMPK also inactivates ACC2 [17] via phosphorylation at the site equivalent to Ser-79 on ACC1 (Ser-221 in human ACC2). A phosphospecific antibody (anti-pACC) recognizes both ACC1 and ACC2 phosphorylated at these sites, and is a widely used marker for AMPK activation. In isolated hepatocytes from AMPK- $\alpha 1 \%$ and $-\alpha 2 \%$ double knockout mice, the signal obtained using this antibody is completely lost, showing that AMPK is responsible for phosphorylation at these sites [18].

There is a large body of evidence to support the link between metabolic disorders, such as obesity and type 2 diabetes, and dysfunctional lipid and energy metabolism causing increases in circulatory and intracellular fatty acids $[10,12,19]$. High levels of fatty acids are toxic to cells and may cause deleterious metabolic abnormalities $[12,19]$. These unwanted effects could be prevented by activation of AMPK and consequent inactivation of ACC2 in peripheral tissues, leading to an increase in fatty acid oxidation $[12,19]$. In addition many cancer cells, including many breast tumours, exhibit a markedly increased rate of fatty acid synthesis [20]. Some breast tumours express high levels of fatty acid synthase (FAS), a key enzyme for fatty acid biosynthesis [21]. FAS is up-regulated in about $50 \%$ of breast cancers, is an indicator of poor prognosis, and is associated with the HER2 oncogene [22-24]. The drug Orlistat $\left(\right.$ Xenical $^{\mathrm{TM}}$ ), which was developed as an inhibitor of gastric and pancreatic lipases and has been approved for weight loss by the FDA, blocks breast cancer cell cycle progression, promotes apoptotic cell death, and transcriptional repression of the HER2 oncogene [25]. In addition to these potentially beneficial effects of AMPK activation on lipid metabolism, AMPK would also be expected to directly inhibit cell growth and proliferation. The major kinase that phosphorylates Thr172 on AMPK has been identified to be the tumour suppressor kinase, LKB1 [26,27]. Although LKB1 is also the upstream kinase for a family of twelve additional AMPKrelated kinases $[28,29]$, many of the tumour suppressor effects of LKB1 are likely to be mediated by AMPK. For example, AMPK activation causes a G1-S phase cell cycle arrest $[30,31]$, while it also inhibits cell growth by switching off the target-of-rapamycin (TOR) pathway [32,33]. Consistent with the idea that AMPK activation might inhibit growth of tumour cells were findings that the oral anti-diabetic drug, metformin, inhibits proliferation of epithelial cells derived from breast, prostate and ovarian cancers, an effect that requires both LKB1 and AMPK [34]. These findings may be clinically relevant, because epidemiological studies show an association between a lower incidence of cancer, including breast cancer, and metformin usage in diabetic patients $[35,36]$.

Despite growing evidence in this arena, little is known about the state of phosphorylation of AMPK, and its downstream target ACC, in human breast cancers. Since malignant cells are likely to have an increased energy demand and may also experience hypoxia and other metabolic stresses, one might speculate that AMPK signalling would be activated. The objective of the present study was to evaluate the status of phosphorylation of AMPK and ACC signalling in human primary breast cancer using immunohistochemistry, and to correlate this with the clinical and pathological characteristics of the tumours.

\section{Methods \\ Patients}

A total of 354 primary human breast cancer specimens were used in this study from two cohorts of patients. The 
first cohort comprised 117 of the pre- and post-menopausal women (aged 34 - 76; median 51 years) with primary breast cancer who participated in the Adjuvant Breast Cancer (ABC) clinical trial from 1992 to 2000 at a single recruiting centre (NHS Tayside) [37].

The second cohort of patients comprised 237 unselected pre- and post-menopausal women (aged 28 - 89; median 62 years) with primary, previously untreated breast cancer who were seen and treated at Tayside University Hospitals, Scotland, from 1997 to 2002. Informed consent was obtained from each patient prior to tissue acquisition. Tumour samples from these patients were constructed on tissue microarray (TMA) slides as described below. Ethics approval was given by the Tayside Research and Ethics committee (Ref. 07/S1402/90).

\section{TMA construction}

A TMA containing up to six $0.6 \mathrm{~mm}$ diameter cores of invasive tumours and normal breast tissue from the same patients was constructed using a manual tissue arrayer (Beecher Instruments Inc., Sun Prairie, WI, USA). Briefly, haematoxylin and eosin (H\&E) stained sections of normal and tumour tissues were reviewed by a single pathologist. Areas suitable for inclusion in the TMA were marked on the slide. Marked slides were matched to their corresponding wax blocks (the donor blocks). The areas of interest were marked on the wax blocks using a marker pen and $0.6 \mathrm{~mm}$ diameter cores of tumour or normal breast tissue were removed and inserted into a pre-cored hole in a recipient paraffin block. Cores were inserted in a grid arrangement. Normal breast tissue cores were constructed alongside the cancerous cores for every patient. Four micron TMA sections were cut, mounted onto poly-Llysine coated glass slides (VWR International Ltd., Lutterworth, UK), and dried for 1 hour at $60^{\circ} \mathrm{C}$ before being deparaffinised in Histoclear (National Diagnostics, Hessle, UK) and xylene, then run through a graded series of alcohol and rehydrated under running water.

\section{Immunohistochemistry (IHC)}

pAMPK (Thr-172) monoclonal antibody and pACC (Ser79) were purchased from Cell Signaling Technology. MIB1 (Anti-Ki67) and anti-HER2 monoclonal antibodies were purchased from Novocastra. Optimal staining conditions such as epitope unmasking, antibody titre, and incubation and visualisation method were validated on conventional whole tissue sections and TMA fragments. Positive controls included normal spleen and breast epithelium for pAMPK and pACC, and breast cancer samples of established ER, HER2 and Ki67. Citric acid buffer, $\mathrm{pH}$ $6.0(10 \mathrm{mM})$ was used as standard microwave-based antigen retrieval method for all proteins except for pACC. Sections were immersed in $10 \mathrm{mM}$ Citric acid buffer, $\mathrm{pH} 6.0$ and subjected to microwave in a pressure vessel for 15 min before then processed on a DAKO autostainer using Vectastatin ${ }^{\circledast}$ ABC kits (Vector Labs, Peterborough, UK) according to the manufacturer's protocol. Ethylene diaminetetraacetic acid disodium salt dihydrate (EDTA) (Sigma product E-5134) for 45 minutes at $94^{\circ} \mathrm{C}$ was used for pACC antigen retrieval. Sections were blocked by either normal goat, horse or rabbit serum containing $10 \%(\mathrm{v} / \mathrm{v})$ from stock avidin solution (Vector Labs) for $20 \mathrm{~min}$ followed by incubation with primary antibody including $10 \%(\mathrm{v} / \mathrm{v})$ from stock biotin solution (Vector Labs) for 1 hour to reduce non-specific background staining. Following incubation with the specific primary antibodies, sections were incubated with either biotinylated anti-rabbit, anti-sheep, or anti-mouse antibody for $30 \mathrm{~min}$ followed by Vectastain ${ }^{\circledast}$ Elite ABC reagent for another $30 \mathrm{~min}$. Liquid diaminobenzidine (DAB; Dako) was used as a chromogenic agent for $5 \mathrm{~min}$ and sections were counterstained with Mayer's haematoxylin. In between each immunostaining step, slides were washed briefly in Tris buffered saline (TBS) buffer, pH 7.6.

\section{Scoring}

Primary TMA scoring was performed by a single author $(\mathrm{SMH})$, verified by an experienced consultant pathologist (SF) and where needed by a specialist breast pathologist (LJ or CAP) using a Nikon Eclipse E600 light microscope with DXM 1200 digital camera and Eclipse-Net software, and Virtual Microscopy in the form of Aperio Technologies, ScanScope XT and Spectrum Plus using TMA software version 9.1. Cores were scored at a magnification of $\times 40$ (Figure 1). Any discrepancies were resolved by subsequent consultation. HER2 immunostaining of cores containing

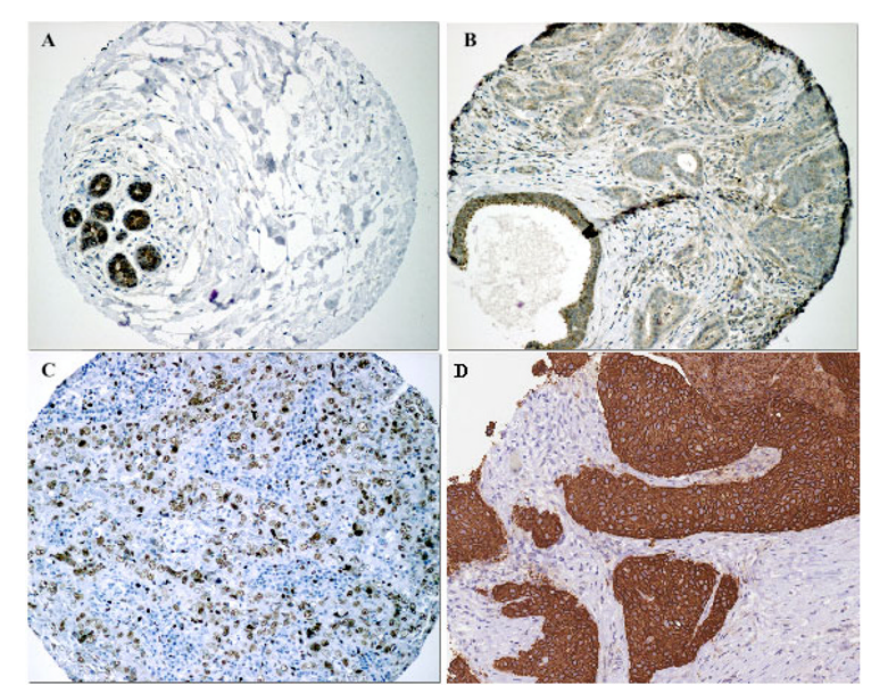

Figure I

Strong staining of AMPK in normal breast lobular unit (A) compared to its light staining in tumour cells (B), examples of a positive Ki67 (C) and HER2 (D). 
Table I: Clinico-pathological characteristics of the patients.

\begin{tabular}{|c|c|c|c|}
\hline Parameter & Cohort I [n (\%)] & Cohort 2 [n (\%)] & $\mathbf{P}$ \\
\hline $\mathbf{N}$ & 117 & 237 & \\
\hline \multicolumn{4}{|c|}{ Menopausal status at diagnosis } \\
\hline Pre- and peri-menopausal & $62(53)$ & $56(24)$ & $<0.001^{*}$ \\
\hline Post-menopausal & $55(47)$ & $18 \mid(76)$ & \\
\hline \multicolumn{4}{|l|}{ Age (years) } \\
\hline Median (range) & $51(34-76)$ & $62(28-89)$ & $<0.001 \sim$ \\
\hline \multicolumn{4}{|l|}{ Tumour size $(\mathrm{cm})$} \\
\hline$\leq 2$ & $61(57)$ & $88(37)$ & $<0.001^{*}$ \\
\hline$>2$ & $46(43)$ & $148(63)$ & \\
\hline \multicolumn{4}{|c|}{ Number of positive lymph nodes } \\
\hline 0 & $48(4 I)$ & $127(54)$ & $\begin{array}{l}0.032 * \dagger \\
0.540 * \ddagger\end{array}$ \\
\hline $\mathrm{I}-3$ & $48(4 I)$ & $74(31)$ & \\
\hline$>3$ & $21(18)$ & $36(15)$ & \\
\hline
\end{tabular}

\section{Histological grade}

\begin{tabular}{|c|c|c|c|}
\hline 1 & $12(10)$ & $34(14)$ & $\begin{array}{l}0.399 * \dagger \\
0.425 * \neq \neq\end{array}$ \\
\hline 2 & $43(38)$ & $91(39)$ & \\
\hline 3 & $59(52)$ & $110(47)$ & \\
\hline \multicolumn{4}{|l|}{ Adjuvant therapy } \\
\hline Endocrine therapy & $18(16)$ & $59(27)$ & N/A \\
\hline Chemotherapy and/or Radiotherapy & $0(0)$ & $54(24)$ & \\
\hline Endocrine + Chemotherapy & $12(10)$ & $10(4)$ & \\
\hline Endocrine + Radiotherapy & $45(38)$ & $70(3 \mathrm{I})$ & \\
\hline Endocrine + Chemo + Radiotherapy & $42(36)$ & $31(14)$ & \\
\hline \multicolumn{4}{|l|}{ Follow up (months) } \\
\hline Median (range) & $73(9-122)$ & $60(1-120)$ & $<0.001^{\sim}$ \\
\hline
\end{tabular}


Table 2: The association between AMPK and all clinico-pathological and immunohistochemical data

\begin{tabular}{|c|c|c|c|c|c|c|c|}
\hline \multirow[b]{2}{*}{ Parameter } & & \multicolumn{3}{|c|}{ Cohort I } & \multicolumn{3}{|c|}{ Cohort 2} \\
\hline & & Positive & Negative & $\mathbf{P}$ & Positive & Negative & $\mathbf{P}$ \\
\hline \multirow[t]{2}{*}{ HER2 } & Positive & 0 & 14 & NS & 0 & 13 & NS \\
\hline & Negative & 12 & 87 & & 3 & 95 & \\
\hline \multirow[t]{2}{*}{ Ki67 } & Positive & 4 & 36 & NS & 7 & 95 & NS \\
\hline & Negative & 8 & 65 & & 11 & 111 & \\
\hline \multirow[t]{2}{*}{$\mathrm{ACC}$} & Positive & 7 & 20 & 0.007 & 7 & 29 & 0.014 \\
\hline & Negative & 5 & 81 & & 12 & 186 & \\
\hline \multirow[t]{2}{*}{$\mathbf{E R} \alpha$} & Positive & 9 & 61 & NS & 12 & 157 & NS \\
\hline & Negative & 3 & 38 & & 7 & 59 & \\
\hline \multirow[t]{2}{*}{ Tumour size $(\mathrm{cm})$} & $\leq 2$ & 7 & 51 & NS & 9 & 79 & NS \\
\hline & $>2$ & 2 & 43 & & 10 & 138 & \\
\hline \multirow[t]{3}{*}{ Positive axillary nodes } & 0 & 8 & 39 & 0.021 & 15 & 111 & 0.087 \\
\hline & $1-3$ & 2 & 44 & & 2 & 71 & \\
\hline & $>3$ & 0 & 12 & & 2 & 35 & \\
\hline \multirow[t]{3}{*}{ Histological grade } & I & 5 & 7 & 0.010 & 6 & 57 & 0.021 \\
\hline & 2 & 2 & 39 & & 7 & 81 & \\
\hline & 3 & 4 & 53 & & 5 & 99 & \\
\hline \multirow[t]{2}{*}{ KM overall survival } & Alive & 11 & 73 & NS & 11 & 154 & NS \\
\hline & Dead & 1 & 28 & & 4 & 35 & \\
\hline
\end{tabular}

tumour were evaluated as $0,1+, 2+$ and $3+$ according to the US FDA-approved scoring guidelines for the Hercep Test [52]: non-specific membrane staining $=0$, membrane or cytoplasmic staining in $<10 \%$ of cells $=1+$, specific membrane staining in $>10 \%$ of cells $=2+$, and strong specific staining in majority of cells $=3+$. HER 2 amplification was confirmed for $2+$ and $3+$ tumours using FISH (Fluorescence In Situ Hybridization). For Ki67 proliferation index (the fraction of proliferating cells), ER $\alpha$, pAMPK and pACC antibody staining of cores containing tumour were assessed using a scoring system based on the Quick Score Method [35]. Immuno-reactivity scored semi-quantitatively for both the intensity and the proportion of cells staining: intensity was given scores $0-3$ (no staining $=0$; light staining $=1$; moderate staining $=2$; strong staining $=$ $3)$ and proportion was given scores $1-6(0-4 \%=1 ; 5-20 \%$ $=2 ; 21-40 \%=3 ; 41-60 \%=4 ; 61-80 \%=5 ; 81-100 \%=6)$. The two scores were then multiplied to obtain the final result of $0-18$. Cores from normal spleen and normal breast tissue were used as control on each slide.

\section{Statistics}

All analyses were performed using Microsoft Excel 2002 SP3 (Microsoft Corporation) and Minitab Release 14.13 (Minitab Inc.). Appropriate choice of $\chi^{2}$ for trend and Fisher's Exact Test (FET) were used for significance of expression, and non-parametric survival plots used the Kaplan-Meier method. When grouping of scores was required for a statistical method, such as Fisher's Exact Test, pAMPK scores were grouped as scores 3 versus scores 0 - 2, chosen because normal breast epithelial cell staining had similar strong staining as the tumour cells scored 3 . The pAMPK results were based on comparing strongly positive AMPK signalling in tumour cells that scored 3 to scores of 0 - 2. For Ki67, scores 0 - 2 were grouped against 3 - 6. For HER2, scores 0 - 1 versus 2 - 3 with FISH verification of the amplification of the latter group; while for $\mathrm{ER} \alpha$, scores 0 - 3 (negative) versus 4 - 18 (positive) was chosen [38]. However, where $\chi^{2}$ for trend was used, the scores were not dichotomised. The null hypothesis was rejected at an $\alpha$ level of $10 \%(\mathrm{p} \leq 0.10)$, and observations considered to be marginal (i.e. of scientific interest and worthy of further investigation) for an $\alpha$ level between $5 \%$ and $10 \%(\mathrm{p} \leq 0.10)$ and significant at $5 \%(\mathrm{p} \leq 0.05)$.

\section{Results}

For the first cohort of the 117 patients, 104 (88.9\%) were infiltrating ductal carcinoma, $3(2.6 \%)$ infiltrating lobular and $10(8.5 \%)$ mixed or other types. All cases were successfully scored for Ki67 and HER2; 3/117 (2.6\%) for pACC, and 4/117 (3.4\%) for pAMPK were not evaluable on the TMAs. 


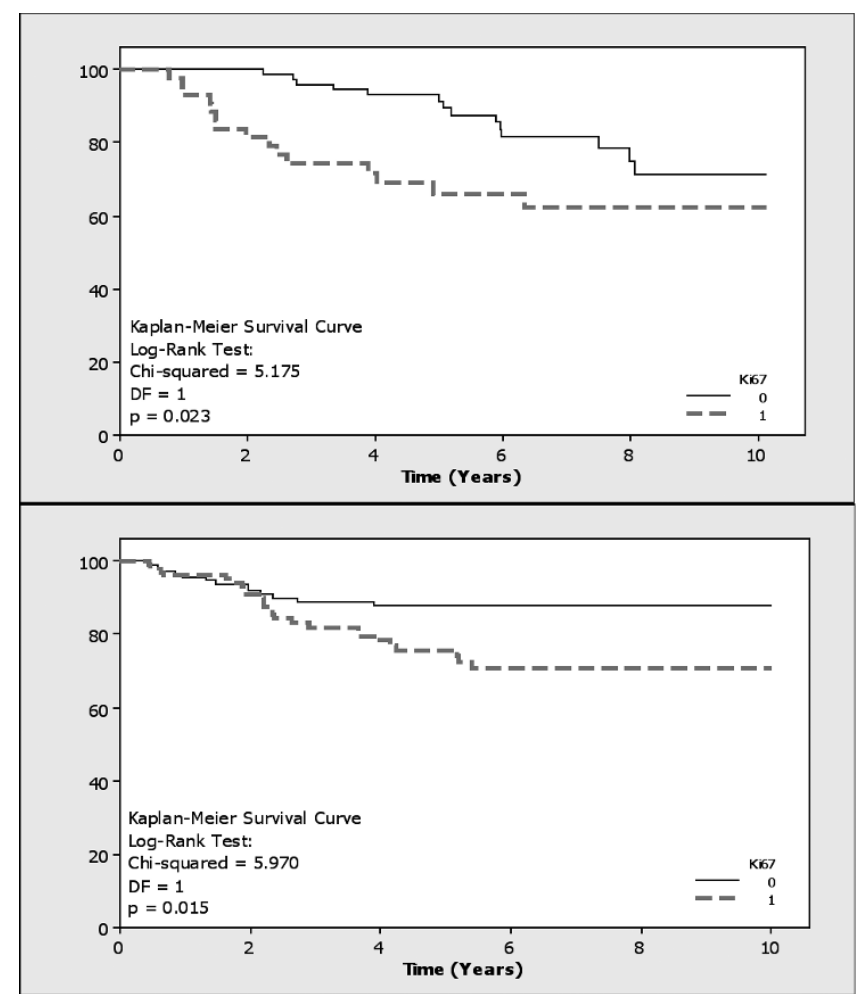

Figure 2

Kaplan-Meier Survival analysis correlating Ki67 expression to overall survival in both cohorts ( $p=$ 0.023 and $p=0.015$ respectively).

In the second cohort of 237 patients, 197 (83.1\%) were infiltrating ductal carcinoma, 16 (6.7\%) infiltrating lobular carcinoma, and 34 (14.3\%) were mixed and other types. One case $(1 / 237(0.4 \%))$ was excluded from scoring for pAMPK and 19/237 (8\%) for pACC were not evaluable (Table 1).

Cytoplasmic staining was seen for pAMPK and, as expected, nuclear staining for Ki67 and ER $\alpha$; combined cell membrane and cytoplasm staining for pACC; cell membrane strongly and cytoplasm lightly for HER2. Normal breast epithelium did not stain for Ki67, HER2 or pACC; however strong staining of normal breast epithelial cytoplasm was observed for pAMPK (Figure 1A).

Reduced AMPK phosphorylation signal (scores 0 - 2) was seen in the vast majority of the breast cancer specimens (101/113 [89.4\%] and 217/236 [91.9\%] of the first and second cohort respectively), as light staining of the cytoplasm (Figure 1B), compared to strong expression in normal breast epithelium (score 3). A significant positive association was seen between pAMPK and pACC signals (FET: $\mathrm{p}=0.007$ and 0.014 respectively). Reduced AMPK phosphorylation signal was associated with higher histological grade $\left(\chi^{2}\right.$ for trend $=6.644, \mathrm{df}=1, \mathrm{p}=0.010$; and $\chi^{2}$ for trend $=5.291, \mathrm{df}=1, \mathrm{p}=0.021$ ). AMPK phosphorylation signal reduction was also associated with axillary node metastasis (FET: $\mathrm{p}=0.061$ and 0.039 respectively) (Table 2 and additional file 1)

Ki67 expression (Figure 1C) was negatively associated with ER status (FET: $\mathrm{p}=0.002$ and $\mathrm{p}<0.001$ respectively) (see additional file 1). It was also associated with higher grade tumours (FET: $\mathrm{p}<0.001$ in both cohorts), increased tumour recurrence (FET: $\mathrm{p}=0.041$ and 0.005 , Relative Risk $(\mathrm{RR})=1.89$ and 1.59 , Odds Ratio $(\mathrm{OR})=2.39$ and 2.47, respectively) and lower overall survival (KaplanMeier Log Rank Test: $\mathrm{p}=0.023$ and $0.015, \mathrm{RR}=1.62$ and 2.13, OR = 2.29 and 23.39, respectively) (Figure 2).

HER2 amplification, found in 11.9\% (14/117) and 13.9\% (32/230) of patients respectively (Figure 1D), was significantly associated with Ki67 expression (FET: $p=0.006$ and 0.021 respectively), higher histological grade (FET: $\mathrm{p}$ $=0.073$ and $<0.001$ respectively), and inversely with ER status (FET: $\mathrm{p}=0.006$ and 0.001 respectively). HER2 positive patients had increased recurrence (FET: $\mathrm{p}=0.027$ and $0.001, \mathrm{RR}=1.72$ and $1.96, \mathrm{OR}=3.75$ and 7.2, respectively); and lower overall survival (Kaplan-Meier Log Rank Test: $\mathrm{p}<0.001$ and $0.075, \mathrm{RR}=2.81$ and $1.99, \mathrm{OR}=5.19$ and 2.3, respectively) (Figure 3 ).

ER positive tumours, identified in $62.6 \%(72 / 115)$ and $73 \%(173 / 237)$ of patients respectively, were associated with HER2 negative (FET: $\mathrm{p}=0.006$ and 0.001 respectively), low Ki67 expression (FET: $\mathrm{p}=0.002$ and $<0.001$ respectively), lower grade tumours (FET: $\mathrm{p}=0.029$ and $<$ 0.001 respectively), and lower disease recurrence (FET: $\mathrm{p}$ $=0.033$ and $<0.001, \mathrm{RR}=1.41$ and $2.75, \mathrm{OR}=2.33$ and 4.36 , respectively). In the second cohort of patients, ER positive patients also lived longer (Kaplan-Meier Log Rank Test: $\mathrm{p}<0.001, \mathrm{RR}=1.44, \mathrm{OR}=5.81$ ) (Figure 4).

\section{Discussion}

Malignant transformation of cells is characterized by insensitivity to growth-inhibitory signals, unlimited replicative potential, angiogenesis, tissue invasion and metastasis [38]. Despite the physiological stresses in cancer cells, and the associated hypoxia in both primary and metastatic cancer [39], malignant cells continue to proliferate and invade. These hallmark characteristics of cancer raise the question of whether dysfunction of AMPK could have a role in malignancy. The aim of this study was to evaluate phosphorylation of AMPK and ACC as markers of AMPK signalling in human breast cancer in relation to clinical and pathological data. 


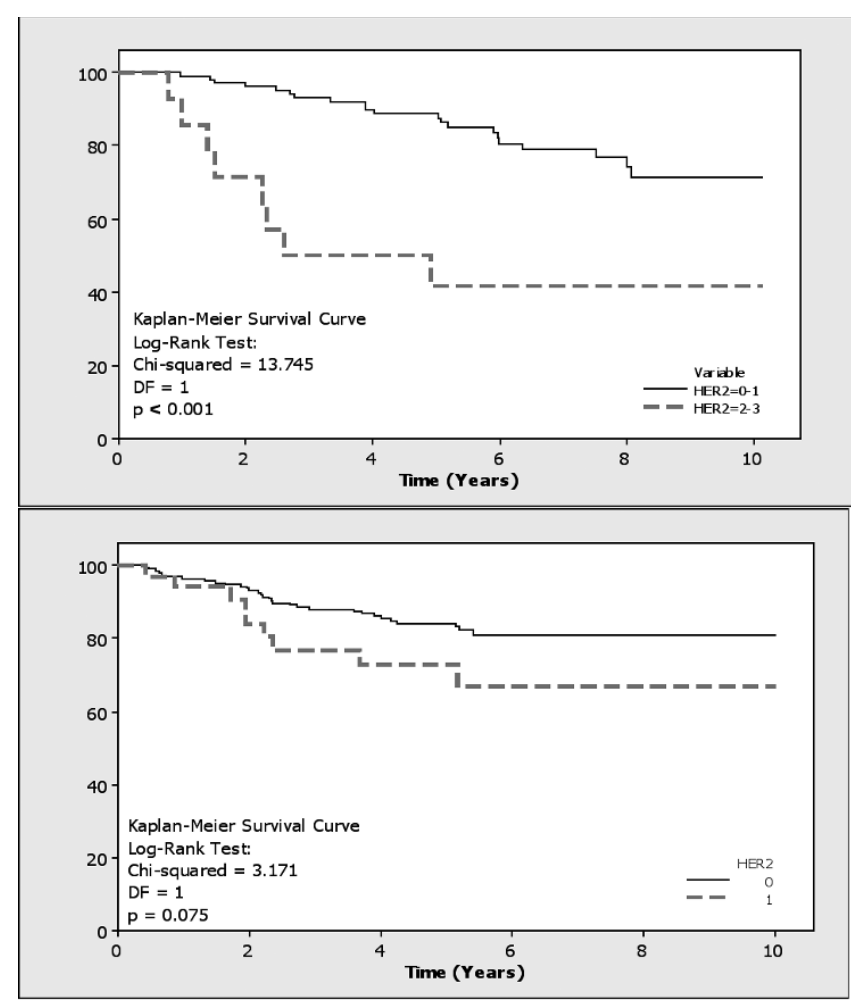

Figure 3

Kaplan-Meier survival analysis correlating HER2 status to overall survival in both cohorts $(p<0.00 I$ and $=0.075$ respectively).

The two cohorts of patients were representative of previously reported breast cancer populations as exemplified by the associations between HER2 amplification, Ki67 expression, ER negative cancers, higher histological grade, Ki67 labelling index [40] and higher disease recurrence and lower overall survival. The significant differences in menopausal status, age, tumour size and node status between the two cohorts (Table 1) perhaps emphasizes the consistent trends and significant associations of AMPK signalling with node status and tumour grade respectively (Table 2). Further possible caveats include the use of IHC rather than western blotting to assess the signalling pathways, although the distribution of signalling in normal and cancerous tissues on IHC allowed localisation of the proteins.

Despite the high energy consuming processes of uncontrolled cellular proliferation in breast cancer, the histological evidence suggests that AMPK does not seem to respond in primary breast cancer. In contrast, normal breast epithelium demonstrated appropriate AMPK staining, but as expected for a quiescent epithelium no activa-

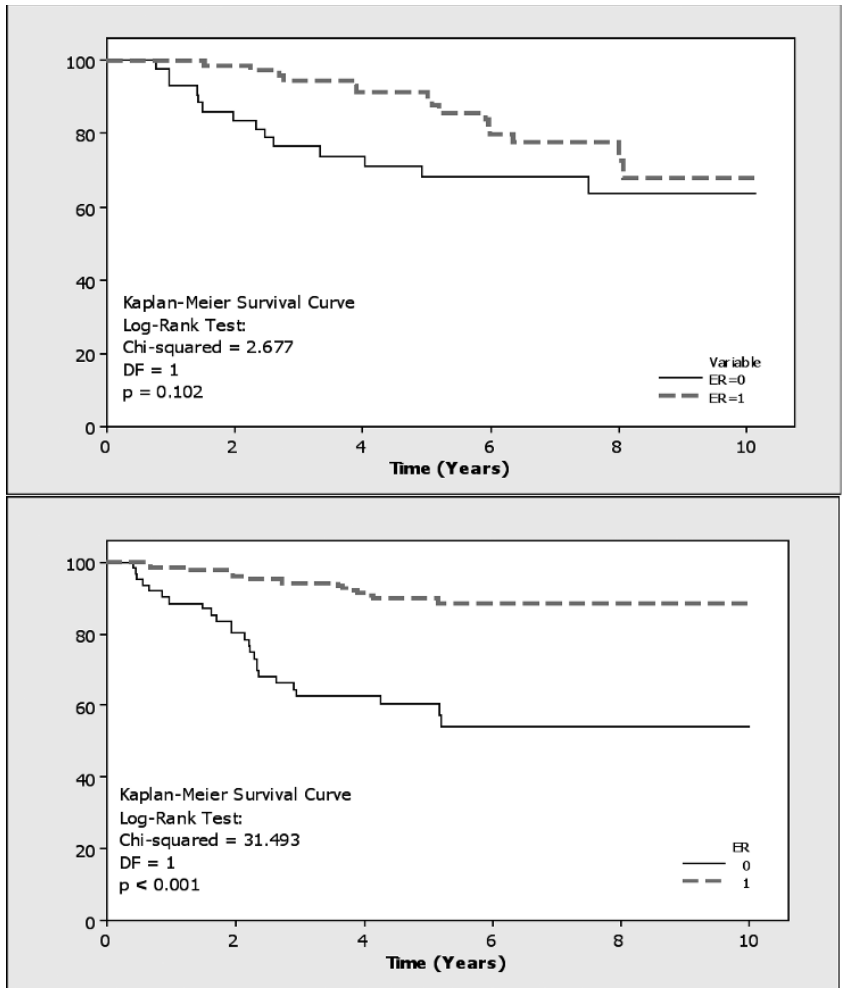

Figure 4

Kaplan-Meier Survival Curve correlating ER status to overall survival in both cohorts $(p=0.102$ and $<0.00$ I respectively).

tion of ACC. Reduced signalling of AMPK phosphorylation in the majority of the breast cancer specimens $(89.4 \%$ in the first and $91.9 \%$ in the second cohort) compared to strong expression in normal breast epithelial cells, and the inverse relationship between staining with histological grade and node status supports the current view that activating this energy-sensing enzyme may be a potential therapeutic avenue in breast cancer [8]. Lower tumour growth fraction, assessed by lower Ki67 proliferation index in patients with activated ACC, a downstream target of AMPK, is consistent with in vitro evidence that AMPK activation leads to reduced proliferation [41] and growth inhibition in epithelial cells [34], also associated with decreased mTOR signalling [42,43]. AMPK activation is known to lead to inhibition of the mTOR pathway $[44,45]$ through phosphorylation of TSC2 [32] and Raptor [33]. Activation of AMPK also directly limits translational initiation and protein synthesis through inhibition of translation elongation factor 2 (EF2) [46]. In this study we have focused on histological evidence for AMPK phosphorylation and its direct downstream target, ACC, as markers of AMPK activation, and have correlated them 
with the functionally important biological markers of breast cancer: ER, Ki67 and HER2.

\section{Conclusion}

In conclusion, the role of AMPK in the mechanism of action of metformin [47-49], evidence in support of a putative relationship between type 2 diabetes and neoplasia with particular reference to breast cancer [50], and the reduced risk of cancer in patients with type 2 diabetes taking metformin compared with those on other medications such as sulphonylureas [35,51], are all indicative of the need to explore this relationship and its potential to discover a novel targeted therapy in breast cancer. AMPK activation is a possible therapeutic target for cancers, since AMPK inhibits mTOR signalling, which in turn inhibit tumour growth in vitro and metastasis in experimental animal models [20]. The data presented here, the first immunohistochemical evidence of AMPK dysfunction in primary breast cancer supports further laboratory and clinical research targeting AMPK by metformin or its analogues in breast cancer.

\section{Abbreviations}

ACC: Acetyl Coenzyme-A Carboxylase; AMPK: Adeonsine Monophosphate Protein Kinase; ATP: Adensine Triphosphate; DAB: Diaminobenzidine; EDTA: Ethylene Diamine Tetra acetic Acid disodium salt dihydrate; FAS: Fatty Acid Synthase; FET: Fisher's Exact Test; FISH: Fluorescence In Situ Hybridization; IHC: Immunohistochemistry; LCFA: Long Chain Fatty Acids; mTOR: mammalian Target Of Rapamycin; NCRI: National Cancer Research Institute; OR: Odds Ratio; pACC: phospho Acetyl Coenzyme-A Carboxylase; pAMPK: phospho Adenosine Monophosphate Protein Kinase; RR: Relative Risk; TBS: Tris-Buffered Saline.

\section{Competing interests}

The authors declare that they have no competing interests.

\section{Authors' contributions}

SMH carried out the TMA staining, immuno-reactivity scoring, initial analysis of the data, and drafted the manuscript. KER and LJ constructed the TMAs. KER wrote the 'method of TMA preparation' part of the materials and methods, and involved in drafting the manuscript. GT and SB guided and helped SMH in TMA staining. LB analysed the data and wrote the statistics section of the manuscript. SF participated rationally in the project design, and with LJ and CAP verified TMA staining and scoring. DGH critically revised the manuscript. AMT substantially contributed to the design of the project, drafting of the manuscript and critically revised it, and gave final approval of the version to be published. All authors read and approved the final manuscript.

\section{Additional material}

\section{Additional file 1}

Supplementary Table. This table shows the inter-relationship between the biomarkers of interest and all clinico-pathological data.

Click here for file

[http://www.biomedcentral.com/content/supplementary/1471-

2407-9-307-S1.doc]

\section{Acknowledgements}

We acknowledge gratefully Breast Cancer Research Scotland and TENOVUS Tayside for funding this project. Grahame Hardie is supported by a Programme Grant from the Wellcome Trust.

\section{References}

I. Hardie DG, Scott JW, Pan DA, Hudson ER: Management of cellular energy by the AMP-activated protein kinase system. FEBS Lett 2003, 546(I): I I3-I20.

2. Hardie DG: AMP-activated/SNFI protein kinases: conserved guardians of cellular energy. Nat Rev Mol Cell Biol 2007, 8(1 0):774-785.

3. Carling D: AMP-activated protein kinase: balancing the scales. Biochimie 2005, 87(I):87-9I.

4. Salt IP, Johnson G, Ashcroft SJ, Hardie DG: AMP-activated protein kinase is activated by low glucose in cell lines derived from pancreatic beta cells, and may regulate insulin release. Biochem J 1998, 335(Pt 3):533-539.

5. Kudo N, Barr AJ, Barr RL, Desai S, Lopaschuk GD: High rates of fatty acid oxidation during reperfusion of ischemic hearts are associated with a decrease in malonyl-CoA levels due to an increase in 5'-AMP-activated protein kinase inhibition of acetyl-CoA carboxylase. J Biol Chem 1995, 270(29): I 75 I 3-I 7520.

6. Marsin AS, Bertrand L, Rider MH, Deprez J, Beauloye C, Vincent MF, Berghe $G$ Van den, Carling D, Hue L: Phosphorylation and activation of heart PFK-2 by AMPK has a role in the stimulation of glycolysis during ischaemia. Curr Biol 2000, I 0(20): | 247-I 255.

7. Hardie DG, Sakamoto K: AMPK: a key sensor of fuel and energy status in skeletal muscle. Physiology (Bethesda) 2006, 21 :48-60.

8. Hadad SM, Fleming S, Thompson AM: Targeting AMPK: a new therapeutic opportunity in breast cancer. Crit Rev Oncol Hematol 2008, 67(I): I-7.

9. Hardie DG, Hawley SA, Scott JW: AMP-activated protein kinase-development of the energy sensor concept. J Physiol 2006, 574(Pt I):7-I5.

10. Ruderman NB, Saha AK, Vavvas D, Witters LA: Malonyl-CoA, fuel sensing, and insulin resistance. Am J Physiol 1999, 276(I Pt I):EI-El8.

II. Munday MR: Regulation of mammalian acetyl-CoA carboxylase. Biochem Soc Trans 2002, 30(Pt 6): 1059-1064.

12. McGarry JD: Banting lecture $200 \mathrm{I}$ : dysregulation of fatty acid metabolism in the etiology of type 2 diabetes. Diabetes 2002, 5 I (I):7-18.

13. Abu-Elheiga L, Matzuk MM, Abo-Hashema KA, Wakil SJ: Continuous fatty acid oxidation and reduced fat storage in mice lacking acetyl-CoA carboxylase 2. Science 200I, 29 I (55 I3):26I3-26I6.

14. Abu-Elheiga L, Brinkley WR, Zhong L, Chirala SS, Woldegiorgis G, Wakil SJ: The subcellular localization of acetyl-CoA carboxylase 2. Proc Natl Acad Sci USA 2000, 97(4): | 444- I449.

15. Ha J, Daniel S, Broyles SS, Kim KH: Critical phosphorylation sites for acetyl-CoA carboxylase activity. I Biol Chem 1994, 269(35):22162-22168.

16. Davies SP, Carling D, Munday MR, Hardie DG: Diurnal rhythm of phosphorylation of rat liver acetyl-CoA carboxylase by the AMP-activated protein kinase, demonstrated using freezeclamping. Effects of high fat diets. Eur J Biochem 1992, 203(3):6I5-623. 
17. Winder WW, Wilson HA, Hardie DG, Rasmussen BB, Hutber CA, Call GB, Clayton RD, Conley LM, Yoon S, Zhou B: Phosphorylation of rat muscle acetyl-CoA carboxylase by AMP-activated protein kinase and protein kinase A. J Appl Physiol 1997, 82(I):219-225.

18. Goransson O, McBride A, Hawley SA, Ross FA, Shpiro N, Foretz M, Viollet B, Hardie DG, Sakamoto K: Mechanism of action of A-76 a valuable tool for activation of AMP-activated protein kinase. J Biol Chem 9662, 282(45):32549-32560.

19. Ceddia RB: Direct metabolic regulation in skeletal muscle and fat tissue by leptin: implications for glucose and fatty acids homeostasis. Int J Obes (Lond) 2005, 29( I 0): I I75- I I 83.

20. Motoshima H, Goldstein BJ, Igata M, Araki E: AMPK and cell proliferation--AMPK as a therapeutic target for atherosclerosis and cancer. I Physiol 2006, 574(Pt I ):63-7I.

21. Kuhajda FP, Pizer ES, Li JN, Mani NS, Frehywot GL, Townsend CA: Synthesis and antitumor activity of an inhibitor of fatty acid synthase. Proc Natl Acad Sci USA 2000, 97(7):3450-3454.

22. Slamon DJ, Clark GM, Wong SG, Levin WJ, Ullrich A, McGuire WL: Human breast cancer: correlation of relapse and survival with amplification of the HER-2/neu oncogene. Science 1987, 235(4785): I77- I82.

23. Slamon DJ, Godolphin W, Jones LA, Holt JA, Wong SG, Keith DE, Levin WJ, Stuart SG, Udove J, Ullrich A: Studies of the HER-2/neu proto-oncogene in human breast and ovarian cancer. Science 1989, 244(4905):707-7I2.

24. Marmor MD, Skaria KB, Yarden Y: Signal transduction and oncogenesis by ErbB/HER receptors. Int J Radiat Oncol Biol Phys 2004, 58(3):903-9l3.

25. Menendez JA, Vellon L, Lupu R: Antitumoral actions of the antiobesity drug orlistat (XenicalTM) in breast cancer cells: blockade of cell cycle progression, promotion of apoptotic cell death and PEA3-mediated transcriptional repression of Her2/neu (erbB-2) oncogene. Ann Oncol 2005, I6(8): I253-1267.

26. Hawley SA, Boudeau J, Reid JL, Mustard KJ, Udd L, Makela TP, Alessi DR, Hardie DG: Complexes between the LKB I tumor suppressor, STRAD alpha/beta and MO25 alpha/beta are upstream kinases in the AMP-activated protein kinase cascade. J Biol 2003, 2(4):28.

27. Woods A, Johnstone SR, Dickerson K, Leiper FC, Fryer LG, Neumann D, Schlattner U, Wallimann T, Carlson M, Carling D: LKB I is the upstream kinase in the AMP-activated protein kinase cascade. Curr Biol 2003, I3(22):2004-2008.

28. Jaleel M, McBride A, Lizcano JM, Deak M, Toth R, Morrice NA, Alessi $D R$ : Identification of the sucrose non-fermenting related kinase SNRK, as a novel LKBI substrate. FEBS Lett 2005, 579(6): $1417-1423$.

29. Lizcano JM, Goransson O, Toth R, Deak M, Morrice NA, Boudeau J, Hawley SA, Udd L, Makela TP, Hardie DG, Alessi DR: LKB I is a master kinase that activates 13 kinases of the AMPK subfamily, including MARK/PAR-I. EMBO / 2004, 23(4):833-843.

30. Imamura K, Ogura T, Kishimoto A, Kaminishi M, Esumi H: Cell cycle regulation via p53 phosphorylation by a 5'-AMP activated protein kinase activator, 5-aminoimidazole-4-carboxamideI-beta-D-ribofuranoside, in a human hepatocellular carcinoma cell line. Biochem Biophys Res Commun 200I, 287(2):562-567.

31. Fogarty S, Hardie DG: C-terminal phosphorylation of LKB I is not required for regulation of AMPK, BRSKI, BRSK2, or cell cycle arrest. J Biol Chem 2008, 284(I):77-84.

32. Inoki K, Zhu T, Guan KL: TSC2 mediates cellular energy response to control cell growth and survival. Cell 2003, I I 5(5):577-590.

33. Gwinn DM, Shackelford DB, Egan DF, Mihaylova MM, Mery A, Vasquez DS, Turk BE, Shaw RJ: AMPK phosphorylation of raptor mediates a metabolic checkpoint. Mol Cell 2008, 30(2):2 I4-226.

34. Zakikhani M, Dowling R, Fantus IG, Sonenberg N, Pollak M: Metformin Is an AMP Kinase-Dependent Growth Inhibitor for Breast Cancer Cells. Cancer Res 2006, 66(2I): I0269-I0273.

35. Evans JM, Donnelly LA, Emslie-Smith AM, Alessi DR, Morris AD: Metformin and reduced risk of cancer in diabetic patients. BMJ 2005, 330(7503): I 304-I305.

36. Bowker SL, Majumdar SR, Veugelers P, Johnson JA: Increased cancer-related mortality for patients with type 2 diabetes who use sulfonylureas or insulin: response to Farooki and Schneider. Diabetes Care 2006, 29(8): 1990-1991.
37. Adjuvant Breast Cancer Trials Collaborative Group: Polychemotherapy for early breast cancer: results from the international adjuvant breast cancer chemotherapy randomized trial. J Natl Cancer Inst 2007, 99(7):506-5I5.

38. Hanahan D, Weinberg RA: The hallmarks of cancer. Cell 2000, I 00(I):57-70.

39. Brizel DM, Rosner GL, Prosnitz LR, Dewhirst MW: Patterns and variability of tumor oxygenation in human soft tissue sarcomas, cervical carcinomas, and lymph node metastases. Int J Radiat Oncol Biol Phys 1995, 32(4): I I 2 |-I I 25.

40. Pinder SE, Wencyk P, Sibbering DM, Bell JA, Elston CW, Nicholson $\mathrm{R}$, Robertson JF, Blamey RW, Ellis IO: Assessment of the new proliferation marker MIBI in breast carcinoma using image analysis: associations with other prognostic factors and survival. $\mathrm{Br}$ / Cancer I995, 7 I(I): |46-|49.

41. Dowling RJ, Zakikhani M, Fantus IG, Pollak M, Sonenberg N: Metformin inhibits mammalian target of rapamycin-dependent translation initiation in breast cancer cells. Cancer Res 2007, 67(22): $10804-10812$

42. Kurose K, Zhou XP, Araki T, Cannistra SA, Maher ER, Eng C: Frequent loss of PTEN expression is linked to elevated phosphorylated Akt levels, but not associated with p27 and cyclin D I expression, in primary epithelial ovarian carcinomas. Am J Pathol 200I, I 58(6):2097-2106.

43. Kimura F, Watanabe J, Hata H, Fujisawa T, Kamata Y, Nishimura Y, Jobo T, Kuramoto H: PTEN immunohistochemical expression is suppressed in $\mathrm{GI}$ endometrioid adenocarcinoma of the uterine corpus. J Cancer Res Clin Oncol 2004, I 30(3): |6|-|68.

44. Kimura N, Tokunaga C, Dalal S, Richardson C, Yoshino K, Hara K, Kemp BE, Witters LA, Mimura O, Yonezawa K: A possible linkage between AMP-activated protein kinase (AMPK) and mammalian target of rapamycin (mTOR) signalling pathway. Genes Cells 2003, 8(I):65-79.

45. Krause $U$, Bertrand L, Hue L: Control of p70 ribosomal protein S6 kinase and acetyl-CoA carboxylase by AMP-activated protein kinase and protein phosphatases in isolated hepatocytes. Eur J Biochem 2002, 269( I 5):375I-3759.

46. Horman S, Browne G, Krause U, Patel J, Vertommen D, Bertrand L, Lavoinne A, Hue L, Proud C, Rider M: Activation of AMP-activated protein kinase leads to the phosphorylation of elongation factor 2 and an inhibition of protein synthesis. Curr Biol 2002, I 2( 16): | 419-1423.

47. Zhou G, Myers R, Li Y, Chen Y, Shen X, Fenyk-Melody J, Wu M, Ventre J, Doebber T, Fujii N, Musi N, Hirshman MF, Goodyear LJ, Moller DE: Role of AMP-activated protein kinase in mechanism of metformin action. J Clin Invest 200 I, I 08(8): I I67-I I74.

48. Hawley SA, Gadalla AE, Olsen GS, Hardie DG: The antidiabetic drug metformin activates the AMP-activated protein kinase cascade via an adenine nucleotide-independent mechanism. Diabetes 2002, 5 I (8):2420-2425.

49. Shaw RJ, Lamia KA, Vasquez D, Koo SH, Bardeesy N, Depinho RA, Montminy M, Cantley LC: The kinase LKB I mediates glucose homeostasis in liver and therapeutic effects of metformin. Science 2005, 3 I 0(5754): I 642-1646.

50. Guastamacchia E, Resta F, Mangia A, Schittulli F, Ciampolillo A, Triggiani $V$, Licchelli B, Paradiso A, Sabba C, Tafaro E: Breast cancer: biological characteristics in postmenopausal type 2 diabetic women. Identification of therapeutic targets. Curr Drug Targets Immune Endocr Metabol Disord 2003, 3(3):205-209.

51. Bowker SL, Majumdar SR, Veugelers P, Johnson JA: Increased cancer-related mortality for patients with type 2 diabetes who use sulfonylureas or insulin. Diabetes Care 2006, 29(2):254-258.

\section{Pre-publication history}

The pre-publication history for this paper can be accessed here:

http://www.biomedcentral.com/1471-2407/9/307/pre pub 